\title{
MAHAN SE TEORIE VAN SEEMAG
}

Deur Lt P.A. Stemmet*

\section{INLEIDING}

"Niemand het die teorie van seemag en vlootstrategie sò direk en ingrypend soos die Amerikaner, Alfred Thayer Mahall, beïnvloed nie".' Sy uiteensetting van die basis van seemag - en die daarmee gepaardgaande grootmoondheidstatus - het plaasgevind in 'n era toe baie moondhede op soek was na 'n teorie wat die grondslag kon vorm vir magsbou. Hy het seemag beskou as 'n noodsaaklike voorvereiste vir die uitbreiding van die nasionale mag en voorspoed van 'n staat. Sy idees vind vandag nog aanklank by strategiese beplanners - die argitek van die moderne Sowjetvloot, Admiraal S.G. Gorshkov, is al 'n kontemporêre Mahan genoem.

\section{AGTERGROND}

Mahan is sedert sy vroegste jare blootgestel aan ' $n$ militêre omgewing - hy is op 27 September 1840 in West Point, New York, gebore, die seun van 'n professor in militêre ingenieurswese by die West Point Militere Akademie. Op sestienjarige leeftyd sluit hy as vaandrig by die Amerikaanse vloot aan en bereik in 1885 die rang van kaptein. Hy doen diens in die Burgeroorlog en sy loopbaan as vlootoffisier neem hom oor die hele wêreld. Sy besoeke aan baie dele van die Britse Ryk laat by hom 'n groot bewondering vir Britse militêre vermoë ontstaan.

'n Keerpunt in sy loopbaan en lewe was die stigting van die Naval War College in 1884. Hy word aangestel as dosent in strategie en taktiek en vlootgeskiedenis. Hier begin hy met die bestudering van "... the concept of sea power and its influence upon empire". 2 In 'n groot aantal artikels begin hy om sy idees in dié verband te propageer, en vind gou ondersteuning by President Rooseveldt. Spoedig geniet hy groot aansien in beide Brittanje en die VSA. Sy idees oor seemag word vervat in drie boeke, The Influence of Sea Power upon History 1660 - 1783, The Influence of Sea Power upon the
French Revolution and Empire 1793 1812 en Sea Power in its Relation to the War of 1812, onderskeidelik gepubliseer in 1890, 1892 en 1905. Hy skryf ook enkele ander boeke, onder andere ' $n$ biografie oor Nelson, waaruit sy bewondering duidelik blyk, en The Interest of Amerlca in Sea Power. Hy sterf in 1914 kort ná die uitbreek van die Eerste Wêreldoorlog. ${ }^{3}$

\section{BEGINSELS VAN MAHAN SE TEORIE VAN SEEMAG}

Mahan was van mening dat beheer oor die see ' $n$ belangrike historiese faktor was wat nooit behoorlik ondersoek of waardeer is nie en dat sodanige ondersoek noodsaaklik was om die veiligheid van die Verenigde State van Amerika (VSA) te verseker. ${ }^{4}$ In sy werk The Influence of Sea Power upon History 1660 - 1783, beskryf hy nie net die geskiedenis van oorloë gedurende hierdie tydperk nie, maar ook interpreteer hy die noue samehang tussen die politieke, diplomatieke, historiese en militêre faktore met die doel om die invloed van die suksesvolle of onsuksesvolle aanwending van seemag op die verloop van die geskiedenis aan te dui. ${ }^{5}$ Volgens hom was seemag 'n noodsaaklike voorvereiste vir die uitbreiding van die nasionale mag en voorspoed van 'n staat. ${ }^{\circ}$

Volgens Mahan is die wêreld se oseane ' $n$ snelweg waarop in alle rigtings gereis kan word, en is watervervoer beide goedkoper en vinniger as landvervoer. Sodoende word die ideale geleentheid tot die ontwikkeling van die handel vir 'n staat wat deur die see begrens word, daargestel. Die ontwikkeling van ' $n$ handelsvloot noop egter 'n staat om ook 'n militêre vloot te ontwikkel om die handelsvloot te beskerm. ${ }^{8}$ Die oseane is ook die ideale medium om militêre mag vinnig oor groot afstande te projekteer. 'n Staat wat beheer oor die see uitoefen, is dus in staat om sy militere mag te multipliseer en te 
verhoed dat die vlootmagte van sy opponente kan konsentreer.9 Mahan was van mening dat seemag Brittanje in staat gestel het om die Britse Ryk op te bou en in stand te hou. Hy het ses beginsels vir die ontwikkeling van seemag geïdentifiseer.

\section{Geografiese ligging}

'n Insulêre, in teenstelling met 'n kontinentale ligging, het die voordeel dat sodanige staat hom nòg op land moet verdedig, nòg oor land hoef uit te brei. Dit was die voordeel van Brittanje bò Holland en Frankryk, wat voortdurend duur landoorloë moes voer om hul onafhanklikheid te behou. 'n Staat kan nie beide ' $n$ groot land- en seemoondheid wees nie. Brittanje se ligging het boonop die voordeel ingehou dat haar seemagte gekonsentreer kon wees, in teenstelling met dié van Frankryk wat versprei was tussen die Atlantiese Oseaan en die Middellandse See. ${ }^{10}$

Verdere belangrike aspekte ten opsigte van geografiese ligging was maklike toegang tot die oop see en beheer oor deurgange tot die wereld se seeverkeerroetes (wat die moontlikheid van h blokkade daarstel)."

\section{Fisiese vorm en Gebiedsgrootte}

Volgens Mahan is die kus van ' $n$ staat die grens daarvan, en moet enige uitbreiding dus seewaarts geskied. Sodanige uitbreiding vergroot die staat se mag en word bepaal deur die aantal hawens, lengte van die kuslyn, fisiese faktore, klimaat en die bevolking. 'n Lang kuslyn met baie goeie hawens is belangrike impulse tot uitbreiding. Frankryk, 'n land met 'n aangename klimaat en hoë binnelandse produksie, was minder geneig as Brittanje, wat nie oor dieselfde voordele heskik het nie, om oor see uit te brei. ${ }^{12}$

\section{Bevolkingsgrootte}

Die verhouding tussen bevolkingsgrootte en die lengte van 'n staat se kuslyn is belangrik uit ' $n$ verdedigingsoogpunt - 'n te klein bevolking kan die voordeel van 'n lang kuslyn tot die nadeel van ' $n$ moeilik verdedigbare grens omskep. ${ }^{13}$ Meer belangrik as bevolkingsgetalle is die aantal mense betrokke by sowel handels- as militêre seevaart. Hoewel die Franse bevolking tydens die oorloë ná die Franse Rewolusie groter was as dié van Brittanje, was meer mense in Brittanje betrokke by seevaart - ' $n$ belangrike magsfaktor. ${ }^{14}$

\section{Nasionale Karakter}

Mahan was van mening dat 'n handelsgeoriënteerde bevolking ' $n$ belangrike stukrag tot die ontwikkeling van 'n handelsvloot is. Die ingesteldheid van die Britse bevolking het bygedra tot die ontwikkeling van oorsese kolonies en die opbou van 'n groot ryk. In teenstelling hiermee was Spanje nie op handel ingestel nie, maar op soek na vinnige rykdom in die vorm van goud en silwer. 'n Groot Spaanse vloot het dus nooit ontwikkel nie en daarom kon Spanje volgens Mahan nie beheer oor sy ryk behou nie. ${ }^{15}$

\section{Regeringsaard}

Besondere regeringsvorme en die daarmee gepaardgaande instellings, sowel as die karakter van regeerders, het volgens Mahan invloed op die ontwikkeling van ' $n$ staat se seemag. Totalitêre regerings kan vinniger en meer doelgerig optree in die opbou van seemag as demokrasieë. Deur die eeue het opeenvolgende Britse regerings een doel voor oë gehad: beheer van die oseane. ${ }^{16}$

\section{Algemene beginsels}

Mahan was van mening dat die belangrike beginsel van landstrategie wat tydens 'n veldslag geld - die konsentrasie van mag - ook met betrekking to seeslae geld. Hoewel Brittanje se vlootmag oor die wêreld versprei was, het die staat se insulêre ligging en relatief klein gebiedsgrootte daartoe bygedra dat beskikbare vlootmag relatief gou gekonsentreer kon word. ${ }^{17}$ Vlootmag moes offensief aangewend word om effektief te kon wees - hy beskou die Franse optrede om seeslae te vermy maar handelsviote aan te val as oneffektief. Volgens hom stel die aanval en uitwis van 'n opponent se vlootmag 'n staat daartoe in staat om die opponent se onverdedigde handelsvloot 
dan uit, te wis, die toevoerlyne na kolonies sodoende af te sny, en die kolonies self dan te verower. ${ }^{18}$

Om die see, en dus die toevoerlyne vir handel te beheer, moes 'n staat oor sowel 'n groot handels- as militêre vloot beskik - die een kan nie sonder die ander bestaan nie: "This command of the sea guaranteed, in war or peace, the continuance of maritime commerce with its exchange of finished produce for supplies and raw materials; a close relation between foreign trade and the navy was thus affirmed." 19

Mahan het sy beginsels van seemag geformuleer in ' $n$ tyd toe dit gelyk het of die vinnige ontwikkeling van tegnologie die bestaan daarvan ongedaan sou maak. Mahan was egter oortuig dat die strategiese lesse van die verlede steeds geld. ${ }^{20}$

Mahan se teorie van seemag spruit uit 'n "philosophy of empire"21 - dit bevat dus elemente van die "lebensraum"gedagte. ${ }^{22}$ ' $n$ Staat is daarop geregtig om sy mag oor sy kuslyne uit te brei internasionale struwelinge kan slegs deur die aanwending van mag opgelos word; mag was die enigste fondament vir vrede. ${ }^{23}$

Mahan het in sy studie van seemag lesse vir die VSA gevind. Hy het betoog dat die VSA meer betrokke in die internasionale magspolitiek moes word en moes begin met die opbou van 'n seemag. Die VSA se twee lang kuslyne, groot aantal hawens, kommersieëlgeoriënteerde bevolking en strategiese ligging naby die Karribiese $\mathrm{See}^{24}$ stel dit in staat om deur die ontwikkeling van seemag ' $n$ wêreldmoondheid te word.

\section{DIE INVLOED VAN MAHAN SE DENKE OP DIE TEORIEË VAN SEEMAG EN VLOOTSTRATEGIEË VAN MOONDHEDE}

Die doel van Mahan se studie was "... to araise his own country from its lethargy and indifference and calling it to assert itself, to take its place among the powers, and to gain for itself a fair share of the good things in life." 25 Sy uiteensetting van die basis van seemag het egter plaasgevind in ' $n$ era toe baie ander moondhede op soek was na 'n teorie van magsbou. Die opkomende magsblokke in Europa en die Verre Ooste wou almal seemag bekom, òf vir selfverdediging òf as ' $n$ dekmantel vir koloniale ekspansionisme. ${ }^{26}$ Mahan se werke het ' $n$ merk gelaat op die verdedigingsbeleide van verskeie moondhede.

\section{Invloed op die VSA}

Mahan het besef dat sy pleidooi dat die VSA 'n groot seemag moes ontwikkel slegs sou slaag as "a fundamental change in the mental attitude of Americans toward maritime affairs" bewerkstellig kon word. ${ }^{27}$ Hy het dus besef dat die VSA moes begin om verby sy eie grense, met ander woorde uitwaarts, te kyk en sy potensiaal as wêreldmoondheid besef. ${ }^{28}$ Mahan het 'n groot aantal tydskrifartikels en briewe aan die pers geskryf in 'n poging om die openbare mening te beïnvloed. Daarin het hy nie net die opbou van mag gepropageer nie, maar ook uitbreiding oor see - die VSA se natuurlike grense was vasgestel, en daarom moes invloed in oorsese gebiede verkry word, veral in die Karribiese Seegebied en die Stille Oseaan. ${ }^{29}$

Mahan se pleidooie het nie op dooie ore geval nie - dit het tot 'n groot mate bygedra tot onderhandelings om die Amerikaans-beheerde Panamakanaal te laat bou, asook tot die anneksasie van die strategies-belangrike Hawaiieilandgroep. ${ }^{30}$

Mahan se werk The Influence of Sea Power upon History 1660-1783 het tot 'n groot mate bygedra tot die Kongres se besluit om "the first real battleships for the Navy" te bou. ${ }^{31}$ Hierdie slaankrag was grootliks verantwoordelik vir die Amerikaanse oorwinning tydens die oorlog met Spanje in 1898. ${ }^{32}$

\section{Invloed op ander state}

Mahan se aanprysing van Britse seemag het tot ' $n$ baie gunstige ontvangs van sy werke in Brittanje gelei. Die Britse Vloot het stadig begin kwyn na die Krimoorlog en vinnige tegnologiese ontwikkelinge het gelei tot onsekerheid met betrekking tot basiese vlootstrategie. Daar is gewonder of groot 
slagskepe nie vervang moet word met goedkoper, vinniger en goedbewapende aanvalsvaartuie nie. Mahan se uiteensetting van seemag het nie alleen belangstelling in die vloot en die rol daarvan gestimuleer nie, maar ook gelei tot 'n doelgerigte vlootbouprogram waarvan die bou van slagskepe die ruggraat was. ${ }^{33}$

Duitsland het op die stadium oor ' $n$ nuwe leierskap en 'n groeiende industriële sektor en bevolking beskik. Die Duitse leiers met drome van buite Europese ekspansionisme het Mahan se teorieë aangegryp as basis van magsverkryging. Veral die Minister van Seevaart van 1897 tot die Eerste Wêreldoorlog, Admiraal Alfred Von Tirpitz, het sy strategie tot 'n groot mate op Mahan se leerstellinge gebaseer. Hy het egter Mahan se doktrine van konsentrasie van mag aangepas tot ' $n$ doktrine van risiko - hy was van mening dat Duitsland Brittanje kan oorwin as die Duitse vloot slegs groot genoeg was om die Britse tuisvloot te oorwin, aangesien Brittanje nie haar hele verspreide vloot vinnig genoeg in die Noordsee sou kon konsentreer nie. ${ }^{34}$ Ook het Tirpitz Mahan se waarskuwings dat seemag nie gelykgestel moet word aan vlootmag nie, dat geen land beide 'n groot see- en landmag kan wees nie en dat Brittanje oor 'n baie beter geografies-strategiese posisie as Duitsland beskik, geïgnoreer. Hierdie beskouings van Von Tirpitz het hom na die Eerste Wêreldoorlog die skyf van felle kritiek gemaak. ${ }^{35}$

Sedert die Tweede Wêreldoorlog het 'n geweldige uitbreiding van die Unie van Sowjet-Sosialistiese Republieke (USSR) se vloot, militêr sowel as kommersieël, plaasgevind. Die argitek van hierdie vlootopbou, Admiraal S.G. Gorshkov, sedert 1955 hoof van die USSR-vloot, het verklaar dat die doel daarvan Russiese beheer oor die oseane is. ${ }^{36}$ Gorshkov se werke oor vlootstrategie toon baie ooreenkoms met dié van Mahan (wat ook dikwels deur hom aangehaal word) en hy is al 'n hedendaagse Mahan genoem. ${ }^{37}$

\section{MAHAN VANDAG}

Sedert Mahan sy beginsels van seemag geformuleer het, het geweldige tegno- logiese ontwikkelinge plaasgevind wat die aard van oorlogvoering ingrypend verander het. Het hierdie ontwikkelinge Mahan se beginsels ongeldig gemaak?

Mahan was so gepre-okkupeer met die slagskipteorie dat hy nie die ontwikkeling van duikboot-oorlogvoering - of die suksesvolle aanwending daarvan om handelvlote te kelder - ingesien het nie. ${ }^{38}$ Ook het hy nie die ontwikkeling van en belang van lugkrag in latere konflikte besef nie. ${ }^{39}$

Hoewel die aanwending van die duikboot deur Duitsland in twee wêreldoorloë groot gevaar vir die Geallieerde seemag ingehou het, is dit tog geneutraliseer deur maatreëls wat gevloei het uit Geallieerde beheer van die see deur die aanwending van die slagskipstrategie. ${ }^{40}$

Die tyd het geleer dat taktiese lugbeheer dikwels afhanklik is van seemag seemag het ontwikkel in lyn met die ontwikkeling van lugkrag deur die ontwikkeling van die vliegdekskip; strategiese vliegvelde word dikwels daargestel deur skeepsvervoerde troepe, vervoer van onderhoudspersoneel, brandstof, voorrade en vliegtuie self vind dikwels per skip plaas. Brittanje se militêre mag is tot 'n groot mate gebou op die land se vermoë tot maklike beheer van seelane. Vliegtuie op land gestasioneer is wel dikwels 'n groot bedreiging vir vlootmagte en kan vlootoperasies beperk, maar kon tot nog toe nie die belang van seemag verminder nie. Tydens die Tweede Wêreldoorlog was die Luftwaffe, gestasioneer in Frankryk en Noorweë, aanvanklik sterker as die Britse lugmag. maar, weens die Geallieerde vlootoormag, kon Duitsland nie beheer van die Atlantiese Oseaan van die Geallieerdes oorneem nie. ${ }^{41}$ Tegnologiese ontwikkelinge het dus nie die permanensie van die beginsels van seemag soos deur Mahan geformuleer, verander nie.

Tot aan die begin van die twintigste eeu het seemag groot voordeel bo landmag gehad: beweeglikheid en gevolglike alomteenwoordigheid. Sedertdien egter het die ontwikkeling van tegnologie in die vorm van beter en vinniger spoor-, lug- en motorvervoer hierdie voordeel uitgewis. Landmag 
beskik nou oor die vermoë om effektiewe beheer oor groot gebiede uit te oefen. ${ }^{42}$ Mahan het die mag van landvervoer onderskat - die ontwikkeling daarvan het die relatiewe belangrikheid van seemag laat afneem en state soos die VSA en USSR potensieël magtig laat word. Dit tas egter nie die geldigheid van die beginsels waarop seemag berus, aan nie.

\section{SLOT}

Dit is dus nie moeilik om beperkinge in Mahan se werke op te spoor nie - hy het die belangrikheid van die see ten opsigte van die land oorbeklemtoon en het nie die invloed wat die duikboot op handelsvlootvernietiging sou hê, besef nie. ${ }^{43}$ Ook die belangrike invloed van ekonomiese voorspoed op seemag is nie voldoende deur Mahan besef nie. ${ }^{44}$ (Die Industriële Rewolusie het 'n belangrike invloed uitgeoefen op die ontwikkeling van Britse seemag tydens die Napoleontiese oorloë, terwyl die afname in Britse seemag nie die gevolg was van neerlae nie, maar van ekonomiese agteruitgang).

Hierdie is egter klein tekortkominge in sy magsleerstellinge, en alhoewel die belangrikheid van landmag relatief tot seemag geweldig toegeneem het (en meer aandag begin kry het as gevolg van die teorieë van Mackinder), het twee wêreldoorloë die beginsels van seemag soos deur Mahan geformuleer, onderskryf (of ten minste nie ongeldig bewys nie). As die vernietigingsvermoë van atoomwapens in die moderne mobiele en amper onopspoorbare kernduikbote in gedagte gehou word, is Mahan se teorie en beginsels van seemag vandag tot' $n$ groot mate geldig in 'n vorm wat hy nie voorsien het nie, $\mathrm{nl}$ dié van ondersese mag. ${ }^{45}$

Die belangrikheid van ' $n$ handelsvloot in die projeksie van seemag is in 1982 tydens die Falkland-oorlog geillustreer toe vyftig handelskepe, onder andere die weeldeskip Queen Elizabeth II, ingespan is om 'n voorraadlyn tussen Brittanje, Ascencioneiland en die oorlogsone te vorm. ${ }^{46}$

Mahan se bydrae was om nie net as 'n geskiedskrywer op te tree nie - in sy werk raak vlootgeskiedenis "... more than a mere chronicle of events; in the hands of this philosopher it became an analysis of the meaning and significance of events with a deduction of their governing principles. "47

\section{VERWYSINGS}

1. Van der Merwe, M.A., Die Ontwikkeling en Ontplooling van die Moderne Sowjet-vloot in die lig van Mahan se Teorie van Seemag, in Regulus, Desember 1982, SA Vlootstafkollege, Muizenberg, $\mathrm{p} 15$.

2. Livezey, W.E., Mahan on Sea Power, University of Oklahoma Press, Norman, $1981, p 11$.

3. Ibid, pp $3-24$.

4. Mahan, A.T., The Influence of Sea Power upon History 1660-1783, University Paperbacks, London,

1965. p xxvii.

5. Ibid, p xxviii.

6. $\underline{\text { lbid }}, \mathrm{p} x \mathrm{xxix}$.

7. Ibid, p 25.

8. lbid, p 26.

9. $\mathrm{lbid}, \mathrm{p} 328$.

10. lbid, p 28.

11. lbid, p 30.

12. libid, pp 35 - 37.

13. Ibid, p 40.

14. lbid, p 45.

15. Ibid, p 51.

16. lbid, p 58.

17. lbid, p xxx.

18. Ibid, pxxxi.

19. lbid, p xxxii; Livezey, op cit, p 52.

20. Livezey, op cit, p 54.

21 . lbid, $\mathrm{p} 34$.

22. lbid, p 325.

23. 1 bid.

24. Mahan, op cit pp 33 en 49.

25. Livezey, op cit, $\mathrm{p} 83$.

26. lbid, p 53; Mahan, op cit, $p x x v i i$.

27. Livezey, op cit, $p 91$.

28. lbid, pp 91 en 94.

29. Ibid, p 92.

30. Ibid, pp 172 en 192.

31. Albion, R.G., Makers of Naval Policy 1798-1947, Naval Institute Press, Maryland, 1980, p 11.

32. lbid.

33. Livezey. op cit, 62-63.

34. lbid pp $67-70$.

35. Ibid, $\mathrm{p} 75$.

36. Nelson, C., The Role of Sea Power in the Sovlet Union's Strategy for World Domination, Militaria, 8/2, 1978, SAW Dokumentasiediens, Pretoria, p 67; Harm, R.H., Die Ontwikkeling van die Sowjet-vloot sedert 1945, Militaria, 9/4, 1979, SAW Dokumentasiediens, 
Pretoria, pp 36-48; Moore, J.E., The Sovlet Navy Today, McDonald and Jane's, London, 1975; Van der Merwe, op cit, pp $15-24$

37. Livezey, op cit p 351.

38. Ibid, p 300 .

39. Ibid, p 306.

40. libid, p 303.

41. lbid, p 307.

42. Ibid, p 317.

43. Mahan, op cit, $p x x x i i$.

44. Livezey, op cit, $p 44$.

45. Lloyd, C.L., Mahan Today, Navy International, Vol 81, No 9, September 1976.

46. Thompson, R., War In Peace, Orbis Publishing, Londenr 1981, p 305.

47. Livezey, op cit, p 45.

* Lt Stemmet is verbonde aan die Burgermag (SA Lugmag)

\section{B IBLIOGRA FIE}

\section{BOEKE:}

Albion, R.G. Makers of Naval Pollcy 1798-1947, Maryland: Naval Institute Press, 1980.

Livezey, W.E. Mahan on Sea Power, Norman University of Oklahoma Press, 1981.

Mahan, A.T. The Influence of Sea Power upon History 1660-1783, London University Paperbacks, 1965.

Moore, J.E. The Soviet Navy Today, London McDonald and Jane's, 1975.

Thompson, R.(Ed) War in Peace, London: Orbis Publishing, 1981.

TYDSKRIFARTIKELS:

Harm, R.H. Die Ontwikkellilg van die Sowjet-vloot sedert 1948. Militaria, 9/4, 1979.

Lloyd, C.L. Mahan Today. Navy International, Vol 1, No 9, September 1976.

Nelson, C. The Role of Sea Power in the Soviet Union's Strategy for World Domination. Militaria, 8/2, 1978.

Van der Merwe, M.A. Dle Ontwikkeling en Ontplooling van die Moderne Sowjetvloot in die lig van Mahan se Teorie van Seemag. Requlus, Desember 1982. 